\title{
Efficacy and safety of alcohol septal ablation in patients over 65 years old with obstructive hypertrophic cardiomyopathy
}

This article was published in the following Dove Press journal:

Clinical Interventions in Aging

3 March 2017

Number of times this article has been viewed

\author{
Laila Cheddadi' \\ Olivier Lairez ${ }^{1-4}$ \\ Thibault Lhermusier ${ }^{1,5}$ \\ Francisco Campelo-Parada' \\ Michel Galinier ${ }^{1,3,4}$ \\ Didier Carrié $1,3,5$ \\ Nicolas Boudou' \\ 'Department of Cardiology, University \\ Hospital of Rangueil, ${ }^{2}$ Department of \\ Nuclear Medicine, ${ }^{3}$ Cardiac Imaging \\ Center, Toulouse University Hospital, \\ ${ }^{4}$ Medical School of Rangueil, ${ }^{5}$ Medical \\ School of Purpan, University Paul \\ Sabatier, Toulouse, France
}

Correspondence: Nicolas Boudou Department of Cardiology, University Hospital of Rangueil, I Avenue Jean Poulhès, Toulouse 31059 Cedex 9 , France

Tel +33 56 I32 33।0

Fax +33 $56 \quad 1322754$

Email boudou.n@chu-toulouse.fr
Background: The performance of alcohol septal ablation (ASA) in elderly symptomatic patients with drug-refractory obstructive hypertrophic cardiomyopathy is still to be confirmed. The objective of this study was to compare the efficacy and safety of ASA in patients under and over 65 years old.

Methods and results: Fifty-one consecutive patients with obstructive hypertrophic cardiomyopathy who underwent ASA were retrospectively included and reviewed for in-hospital major acute cardiac events and follow-up. Twenty-eight patients were over 65 years old. Left ventricular outflow tract obstruction at rest, use of diuretic and average dose of diuretic were higher in patients over 65 years old. There was no difference in hospital stay between patients under and over 65 years old. Among patients over 65 years old, 2 (7\%) died before being discharged. Major acute cardiac events were more frequent in patients over 65 years old in comparison with younger patients ( $43 \%$ versus $9 \%$, respectively, $P=0.007$ ). The average follow-up duration was $16 \pm 15$ months. There was no difference between patients under and over 65 years old regarding the efficacy of the procedure with a decrease of the New York Heart Association class of $1.3 \pm 0.6$ and $1.4 \pm 0.7(P=0.510)$ and the maximum left ventricular outflow tract gradient of $86 \pm 57$ and $81 \pm 36 \mathrm{mmHg}(P=0.733)$, respectively.

Conclusion: Elderly patients have the same benefits as younger patients after ASA but have more complications including mortality events.

Keywords: alcohol septal ablation, hypertrophic cardiomyopathy, elderly

\section{Introduction}

Percutaneous interventions have paved the way for new therapeutic areas on heart with a minimally invasive approach competing heart surgery. Consequently, indications of percutaneous interventions have grown over the last decade, particularly for elderly patients, who are frequently challenged for surgical approaches. Although percutaneous interventions have been well validated in most of the patients, their efficacy and safety in elderly patients continue to be debated. The use of interventional cardiology in continually aging population is known to carry a higher risk of complications, and because elderly patients are usually excluded from clinical studies, the performance of percutaneous intervention on elderly patients is still to be confirmed. This is particularly true for alcohol septal ablation (ASA) in symptomatic patients with drug-refractory obstructive hypertrophic cardiomyopathy (HCM). Although the comparison of myomectomy and ASA by randomized clinical trial seems impossible to perform, ${ }^{1}$ ASA is widely used in Europe. It is nowadays admitted that short- and long-term outcomes of ASA are mostly favorable. ${ }^{2,3}$ This is well validated for young- and middle-age patients. ${ }^{4}$ 
Although few studies suggest that the age is an independent predictor of mortality after ASA, ${ }^{5}$ other studies suggest that the hemodynamic benefit is distinct according to the age of patients. ${ }^{6}$ Efficacy and safety of ASA in elderly patients remain to be confirmed.

The objective of this study was to compare the efficacy and safety of ASA in patients under and over 65 years old.

\section{Methods}

\section{Study sample}

Fifty-one consecutive patients with obstructive HCM who underwent ASA in the University Hospital of Rangueil, Toulouse, France, between January 2010 and July 2015 were retrospectively included. The clinical diagnosis of obstructive HCM was based on the demonstration by bidimensional echocardiography of a nondilated and hypertrophied left ventricle (maximum left wall thickness $\geq 15 \mathrm{~mm}$ ) in the absence of another cardiac or systemic disease that could produce a similar degree of hypertrophy. ${ }^{7-9}$ Indication of ASA was retained according to the European Society of Cardiology guidelines in patients with symptoms and left ventricular (LV) outflow tract obstruction $\geq 50 \mathrm{mmHg}$ at rest or after exercise despite an optimal medical treatment. Demographic data, cardiovascular risk factors, electrocardiography, biochemistry, medication and procedural characteristics were abstracted from medical records.

The study was approved by our institutional review board (research ethics committee of the university hospital of Toulouse), and all patients were informed of the study design. Due to the retrospective design of the study the research ethics committee of the university hospital of Toulouse deemed written informed consent not necessary.

\section{Echocardiography}

All patients underwent a transthoracic echocardiography examination at baseline, during the procedure of ASA and during the follow-up with a commercially available ultrasound Vivid E9 system (GE Vingmed Ultrasound AS, Horten, Norway) or Philips IE33 (Philips Medical Systems, the Netherlands) using a $2.5 \mathrm{MHz}$ transducer. A complete M-mode and two-dimensional gray scale echocardiography including the three standard apical views (four, three and two chambers) using high frame rates $(>60$ frames/sec) were performed for each patient. All echocardiographic data were synchronized to the electrocardiogram, and acquisition was performed during breath hold. The peak instantaneous LV outflow tract gradient was measured with continuous-wave Doppler in the apical five-chamber view with the simplified Bernoulli equation.
Patients with LV outflow tract obstruction $<50 \mathrm{mmHg}$ at rest were tested by exercise echocardiography. Maximum LV wall thicknesses were measured in parasternal long-axis view. LV end-diastolic, end-systolic volumes and ejection fractions were measured using Simpson's biplane method.

\section{Cardiac magnetic resonance}

Cardiac magnetic resonance (CMR) was performed on a 1.5-T MR commercial scanners, either Avanto, Siemens Medical Solutions (Erlangen, Germany) or Intera, Philips Medical Systems (Best, the Netherlands) using a 12-element phasedarray cardiac coil with vector-cardiac gating in all patients. Following scout imaging, balanced steady-state free precession breath-hold images were acquired: slice thickness $6 \mathrm{~mm}$ (long-axis and four-chamber views) or 8-10 mm (contiguous short-axis views [no gap between slices, from the atrioventricular ring to the apex]). Subsequently, delayed contrastenhanced CMR images were obtained in the same long-axis, four-chamber and short-axis orientations 10 minutes after injection of $0.2 \mathrm{mmol} / \mathrm{kg}$ of gadolinium dimenglumine (Magnevist, Berlex Imaging, Wayne, NJ, USA) using a phasesensitive inversion recovery spoiled gradient echo sequence. LV ejection fraction and mass were calculated using clinically available software (Argus [Siemens Medical Solutions] and ViewForum [Philips Medical Systems]). Left atrial diameter was measured in the long-axis and four-chamber view.

\section{Alcohol Septal Ablation}

A temporary pacemaker was placed in all patients except those who already had a permanent pacemaker. A 6F guiding catheter was engaged in the ostium of the left main coronary artery, and a 10-15×1.5-3-mm over-the-wire balloon catheter was advanced over a 0.014 -inch wire into the target septal perforator artery. For two patients, the target septal artery was reached through the right coronary artery. Myocardial contrast echocardiography was used through the balloon lumen to delineate the culprit septal segments. Ethanol 1-5 mL was injected into the artery supplying the culprit septal segments and left in place for 5 minutes. If complete heart block was present at 48 hours after the procedure, a permanent dualchamber pacemaker was implanted.

\section{Follow-up}

In-hospital major acute cardiac events (MACE) were defined by death and/or cardiac tamponade and/or third-degree atrioventricular block requiring permanent stimulation and/or hemorrhage from the vascular path requiring transfusion. Follow-up consisted of a functional and echocardiographical assessment 
and was performed by review of the patient's last hospital consultation.

\section{Statistical analysis}

Continuous variables were expressed as mean \pm standard deviation. Nominal values were expressed as numbers and percentages. Univariate analyses were performed using the Mann-Whitney rank sum test for continuous variables and the Fisher's exact test for categorical variables for intergroup comparisons. Association between nominal variables was investigated by the Fisher's exact test. Comparisons of continuous variables were performed by a Mann-Whitney $U$ test or Spearman's correlation when appropriate. Simple linear regression was first performed between MACE and all subject characteristics. Then, two models of multivariate analysis were performed using a multiple regression model including, among baseline characteristics, all univariate parameters with a $P$-value $<0.10$ and either age in years (model 1 ) or age over 65 years (model 2 ). All statistical analyses were performed using SPSS version 20.0 (SPSS Inc., Chicago, IL, USA) and $P<0.05$ defined statistical significance.

\section{Results}

\section{Baseline characteristics}

The average population age was $67 \pm 12$ years. Twenty-eight patients were over 65 years old. All patients had symptoms with a balanced distribution of poor dyspnea (New York Heart Association [NYHA] class II) and severe dyspnea (NYHA class III and IV), without any difference between patients under and over 65 years old. The demographic, echocardiographic and CMR characteristics of patients are listed in Table 1. Comparing to patients under 65 years old, there were more females in the group over 65 years old, with a smaller weight and a trend to a higher rate of arterial hypertension. Younger patients had more history of smoking habits and a higher indexed LV mass. LV outflow tract obstruction at rest, use of diuretic and average dose of diuretic were higher in patients over 65 years old.

\section{ASA procedure}

Most of the patients ( $88 \%$ ) had radial access, without any difference between young and elderly patients $(P=0.242)$. There was no difference between young and elderly patients in terms of the morphine administration during the procedure with doses of $8.3 \pm 3.6$ and $7.2 \pm 2.1 \mathrm{mg}(P=0.081)$, respectively. As shown in Table 1, the target septal artery was the first one for most of the patients over 65 years old, whereas $35 \%$ of the patients under 65 years old required the ablation of another septal artery: most of the time the second one, except for two patients who required the ablation of the septal artery from the posterior descending artery.

\section{Safety of the procedure}

The average hospital stay was $8 \pm 3$ and $9 \pm 4$ days for patients under and over 65 years old, respectively $(P=0.633)$.

Table 2 shows in-hospital cardiac events after ASA among patients under and over 65 years old. Among patients over 65 years old, 2 (7\%) died before being discharged. There was no fatal case in patients under 65 years old. MACE, defined by death and/or cardiac tamponade and/or third-degree atrioventricular block requiring permanent stimulation and/or hemorrhage from the vascular path requiring transfusion, were more frequent in patients over 65 years old in comparison with younger patients (12 [43\%] versus 2 [9\%], respectively, $P=0.007$ ).

As shown in Table 3, by univariate analysis, age, age over 65 years old, female and hypercholesterolemia were associated with a risk of increase for MACE after ASA. There was a trend for decreased risk with radial access. After multivariate analysis, there was still a trend of increased risk for MACE with age, and particularly age over 65 years, but the association was no longer statistically significant.

\section{Efficacy of the procedure}

The average duration of follow-up was $22 \pm 19$ and $16 \pm 15$ months for patients under and over 65 years old, respectively $(P=0.354)$. There was no difference between patients under and over 65 years old regarding the efficacy of the procedure with a decrease of the NYHA class of $1.3 \pm 0.6$ and $1.4 \pm 0.7$ $(P=0.510)$ and the maximum $\mathrm{LV}$ outflow tract gradient of $86 \pm 57$ and $81 \pm 36 \mathrm{mmHg}(P=0.733)$, respectively. The average NYHA class at the time of follow-up was $1.3 \pm 0.4$ and 1.2 $\pm 0.4(P=0.359)$ for patients under and over 65 years old, respectively. The impact of the procedure on the NYHA class for both groups is illustrated in Figure 1.

\section{Discussion}

The incidence of cardiovascular disease rises with age, and age itself is considered as a risk factor for the development of cardiovascular diseases. Clinical and experimental evidence proves that the aging process promotes structural and functional remodeling of the heart, which occurs even in healthy older adults in the absence of an overt cardiovascular disease. It is legitimate to suppose that age-related effects on heart can modify the natural time course of heart disease. HCM may develop in various age groups as a consequence of different 
Table I Demographic, echocardiographic, CMR and procedural characteristics of patients

\begin{tabular}{|c|c|c|c|c|}
\hline & $\begin{array}{l}\text { All patients, } \\
n=51\end{array}$ & $\begin{array}{l}\text { Patients } \leq 65 \\
\text { years, } n=23\end{array}$ & $\begin{array}{l}\text { Patients }>65 \\
\text { years, } n=28\end{array}$ & $P$-value \\
\hline Age (range), years & $67 \pm 12(33-86)$ & $56 \pm 9(33-65)$ & $75 \pm 6(66-86)$ & $<0.0001$ \\
\hline Male, n (\%) & $23(45)$ & $17(74)$ & $6(2 I)$ & $<0.0001$ \\
\hline Weight, kg & $74 \pm 14$ & $80 \pm 14$ & $68 \pm 12$ & 0.004 \\
\hline Height, m & $1.83 \pm 0.24$ & $\mathrm{I} .8 \mathrm{I} \pm 0.23$ & $1.85 \pm 0.24$ & 0.788 \\
\hline Body mass index, $\mathrm{kg} / \mathrm{m}^{2}$ & $27.2 \pm 4.1$ & $27.9 \pm 3.7$ & $26.6 \pm 4.3$ & 0.208 \\
\hline NYHA functional class & $2.4 \pm 0.9$ & $2.3 \pm 1.0$ & $2.5 \pm 0.8$ & 0.617 \\
\hline \multicolumn{5}{|l|}{ NYHA stage, n (\%) } \\
\hline II & $24(47)$ & II (48) & $13(46)$ & 0.228 \\
\hline $\mathrm{III} / \mathrm{IV}$ & $22(43)$ & $12(52)$ & $15(54)$ & 0.572 \\
\hline Angina & II (22) & $5(22)$ & $6(2 I)$ & 0.621 \\
\hline Syncope & II (22) & $7(30)$ & $4(14)$ & 0.146 \\
\hline \multicolumn{5}{|l|}{ Medical history, n (\%) } \\
\hline Diabetes mellitus & $9(18)$ & $4(17)$ & $5(18)$ & 0.630 \\
\hline Hypertension & $3 I(6 I)$ & II (48) & $20(7 \mathrm{I})$ & 0.076 \\
\hline Hypercholesterolemia & $23(45)$ & $9(39)$ & $14(50)$ & 0.311 \\
\hline Current smoking & $7(14)$ & $4(17)$ & $3(I I)$ & 0.387 \\
\hline Smoking history & $13(26)$ & $9(39)$ & $4(14)$ & 0.044 \\
\hline Atrial fibrillation & $16(31)$ & $7(30)$ & $9(32)$ & 0.570 \\
\hline Maximum LV thickness, mm & $20 \pm 3$ & $20 \pm 3$ & $20 \pm 2$ & 0.394 \\
\hline Indexed LV mass, $g / \mathrm{m}^{2}$ & $92 \pm 23$ & $99 \pm 23$ & $83 \pm 20$ & 0.044 \\
\hline Late gadolinium enhancement, n (\%) & $12(24)$ & $9(39)$ & $3(\mathrm{II})$ & 0.126 \\
\hline LV ejection fraction (\%) & $69 \pm 10$ & $67 \pm 11$ & $72 \pm 8$ & 0.519 \\
\hline LVOT gradient $>30 \mathrm{mmHg}$ at rest, $\mathrm{n}(\%)$ & $45(88)$ & $18(78)$ & $27(96)$ & 0.058 \\
\hline LVOT gradient at rest, $\mathrm{mmHg}$ & $88 \pm 45$ & $76 \pm 49$ & $98 \pm 4 I$ & 0.017 \\
\hline Maximum LVOT gradient, mmHg & $102 \pm 45$ & $103 \pm 56$ & $102 \pm 35$ & 0.557 \\
\hline \multicolumn{5}{|l|}{ Medications, n (\%) } \\
\hline Diuretic & $14(27)$ & $3(13)$ & II (39) & 0.036 \\
\hline Diuretic posology, mg/day & $34 \pm|4|$ & $6 \pm 19$ & $57 \pm 188$ & 0.032 \\
\hline $\begin{array}{l}\text { Angiotensin-converting enzyme inhibitors } \\
\text { or angiotensin receptor blockers }\end{array}$ & $18(35)$ & $6(26)$ & $12(43)$ & 0.171 \\
\hline Beta-blockers & $44(86)$ & $20(86)$ & $24(86)$ & 0.613 \\
\hline Calcium-channel blocker & II (22) & $6(26)$ & $5(18)$ & 0.355 \\
\hline Antiarrhythmic & $9(18)$ & $4(17)$ & $5(18)$ & 0.630 \\
\hline Creatinine, $\mu \mathrm{mol} / \mathrm{L}$ & $93 \pm 70$ & $83 \pm 16$ & $102 \pm 93$ & 0.895 \\
\hline \multicolumn{5}{|l|}{ Procedure } \\
\hline Radial access, n (\%) & $45(88)$ & $22(96)$ & $24(86)$ & 0.242 \\
\hline Ethanol volume, $\mathrm{mL}$ & $2.3 \pm 0.7$ & $2.2 \pm 0.5$ & $2.4 \pm 0.9$ & 0.603 \\
\hline First septal artery ablation, n (\%) & $39(76)$ & $15(65)$ & $25(89)$ & 0.041 \\
\hline Peak CK, U/L & $991 \pm 429$ & $913 \pm 453$ & $|, 05| \pm 408$ & 0.232 \\
\hline Peak CK/septal thickness, U/L per cm & $503 \pm 225$ & $455 \pm 221$ & $540 \pm 225$ & 0.209 \\
\hline
\end{tabular}

Note: Data presented as mean \pm standard deviation (range) or $n(\%)$.

Abbreviations: CK, creatine kinase; LV, left ventricular; LVOT, left ventricular outflow tract; NYHA, New York Heart Association.

Table 2 In-hospital cardiac events after alcohol septal ablation

\begin{tabular}{lllll}
\hline & All patients, n=5 I & Patients $\leq \mathbf{6 5}$ years, $\mathbf{n = 2 3}$ & Patients $>\mathbf{6 5}$ years, $\mathbf{n = 2 8}$ & P-value \\
\hline Death, n (\%) & $2(4)$ & $0(0)$ & $2(7)$ & 0.296 \\
Tamponade, n (\%) & $2(4)$ & $0(0)$ & $2(7)$ & 0.296 \\
Permanent stimulation, n (\%) & II (22) & $2(9)$ & $9(32)$ & 0.043 \\
Hemorrhage from the vascular path, n (\%) & $4(8)$ & $0(0)$ & $4(14)$ & 0.082 \\
Major acute cardiac events, n (\%) & I4 (27) & $2(9)$ & $12(43)$ & 0.007 \\
\hline
\end{tabular}


Table 3 Multivariate analysis for MACE

\begin{tabular}{|c|c|c|c|c|c|c|}
\hline & \multicolumn{6}{|l|}{ MACE } \\
\hline & \multicolumn{2}{|l|}{ Univariate } & \multicolumn{2}{|c|}{ Multivariate model I } & \multicolumn{2}{|c|}{ Multivariate model 2} \\
\hline & $\mathbf{H R} \pm \mathbf{S D}$ & $P$-value & $\mathbf{H R} \pm \mathbf{S D}$ & $P$-value & $\mathbf{H R} \pm \mathbf{S D}$ & $P$-value \\
\hline Age (range), years & $0.014 \pm 0.006$ & 0.005 & $0.010 \pm 0.005$ & $0.07 I$ & N/A & \\
\hline Age $>65$ years & $0.38 \mathrm{I} \pm 0.1111$ & 0.006 & $N / A$ & & $0.249 \pm 0.135$ & 0.071 \\
\hline Male & $-0.293 \pm 0.123$ & 0.037 & $-0.134 \pm 0.123$ & 0.280 & $-0.083 \pm 0.135$ & 0.543 \\
\hline Weight, kg & $0.007 \pm 0.004$ & 0.250 & & & & \\
\hline Height, m & $0.178 \pm 0.45 \mid$ & 0.796 & & & & \\
\hline Body mass index, $\mathrm{kg} / \mathrm{m}^{2}$ & $-0.016 \pm 0.016$ & 0.465 & & & & \\
\hline NYHA functional class & $0.042 \pm 0.117$ & 0.887 & & & & \\
\hline \multicolumn{7}{|l|}{ NYHA stage } \\
\hline II & $0.036 \pm 0.143$ & 0.801 & & & & \\
\hline III/IV & $-0.036 \pm 0.143$ & 0.801 & & & & \\
\hline Angina & $-0.002 \pm 0.140$ & 0.653 & & & & \\
\hline Syncope & $0.216 \pm 0.101$ & 0.128 & & & & \\
\hline \multicolumn{7}{|l|}{ Medical history } \\
\hline Diabetes mellitus & $-0.054 \pm 0.129$ & 0.705 & & & & \\
\hline Hypertension & $-0.136 \pm 0.146$ & 0.342 & & & & \\
\hline Hypercholesterolemia & $0.325 \pm 0.133$ & 0.020 & $0.217 \pm 0.117$ & 0.070 & $0.242 \pm 0.115$ & 0.061 \\
\hline Current smoking & $0.010 \pm 0.144$ & 0.944 & & & & \\
\hline Previous smoking & $0.144 \pm 0.146$ & 0.312 & & & & \\
\hline Atrial fibrillation & $0.058 \pm 0.145$ & 0.688 & & & & \\
\hline Maximum LV thickness, mm & $-0.022 \pm 0.285$ & 0.823 & & & & \\
\hline Indexed LV mass, $g / \mathrm{m}^{2}$ & $0.002 \pm 0.003$ & 0.584 & & & & \\
\hline Late gadolinium enhancement & $0.012 \pm 0.180$ & 0.951 & & & & \\
\hline LV ejection fraction, \% & $0.003 \pm 0.010$ & 0.655 & & & & \\
\hline LVOT gradient $>30 \mathrm{mmHg}$ at rest & $0.088 \pm 0.124$ & 0.538 & & & & \\
\hline LVOT gradient at rest, $\mathrm{mmHg}$ & $0.00 I \pm 0.001$ & 0.170 & & & & \\
\hline Maximum LVOT gradient, $\mathrm{mmHg}$ & $0.001 \pm 0.001$ & 0.363 & & & & \\
\hline \multicolumn{7}{|l|}{ Medications } \\
\hline Diuretic & $0.212 \pm 0.151$ & 0.135 & & & & \\
\hline Diuretic posology, mg/day & $0.00 I \pm 0.002$ & 0.154 & & & & \\
\hline $\begin{array}{l}\text { Angiotensin-converting enzyme inhibitors } \\
\text { or angiotensin receptor blockers }\end{array}$ & $-0.087 \pm 0.138$ & 0.546 & & & & \\
\hline Beta-blockers & $-0.010 \pm 0.140$ & 0.944 & & & & \\
\hline Calcium-channel blocker & $0.105 \pm 0.149$ & 0.465 & & & & \\
\hline Antiarrhythmic & $0.061 \pm 0.149$ & 0.671 & & & & \\
\hline Creatinine, $\mu \mathrm{mol} / \mathrm{L}$ & $0.002 \pm 0.003$ & 0.102 & & & & \\
\hline \multicolumn{7}{|l|}{ Procedure } \\
\hline Radial access & $-0.240 \pm 0.161$ & 0.089 & $-0.236 \pm 0.194$ & 0.231 & $-0.228 \pm 0.195$ & 0.247 \\
\hline Ethanol volume, $\mathrm{mL}$ & $0.082 \pm 0.089$ & 0.478 & & & & \\
\hline First septal artery ablation & $0.109 \pm 0.127$ & 0.447 & & & & \\
\hline Peak CK, U/L & $0.00 I \pm 0.001$ & 0.798 & & & & \\
\hline Peak CK/septal thickness, U/L per $\mathrm{cm}$ & $0.001 \pm 0.001$ & 0.297 & & & & \\
\hline
\end{tabular}

Abbreviations: CK, creatine kinase; HR, hazard ratio; LV, left ventricular; LVOT, left ventricular outflow tract; MACE, major acute cardiac events; N/A, non applicable; NYHA, New York Heart Association; SD, standard deviation.

pathological processes ${ }^{10}$ and may be a different disease in young and elderly patients. Whether the disease takes the same form in the elderly than in the young or middle-aged patients has not been clarified. ${ }^{11}$ Consequently, the benefits and the risks of ASA may change with age. Our study shows that 1) ASA has the same efficacy among patients under and over 65 years old; and 2) patients over 65 years old have more in-hospital complications of the procedure.

Regarding the benefits of ASA in elderly when compared with younger patients, our results are consistent with the previous ample studies where ASA produced significant and similar improvements in LV outflow tract obstruction 


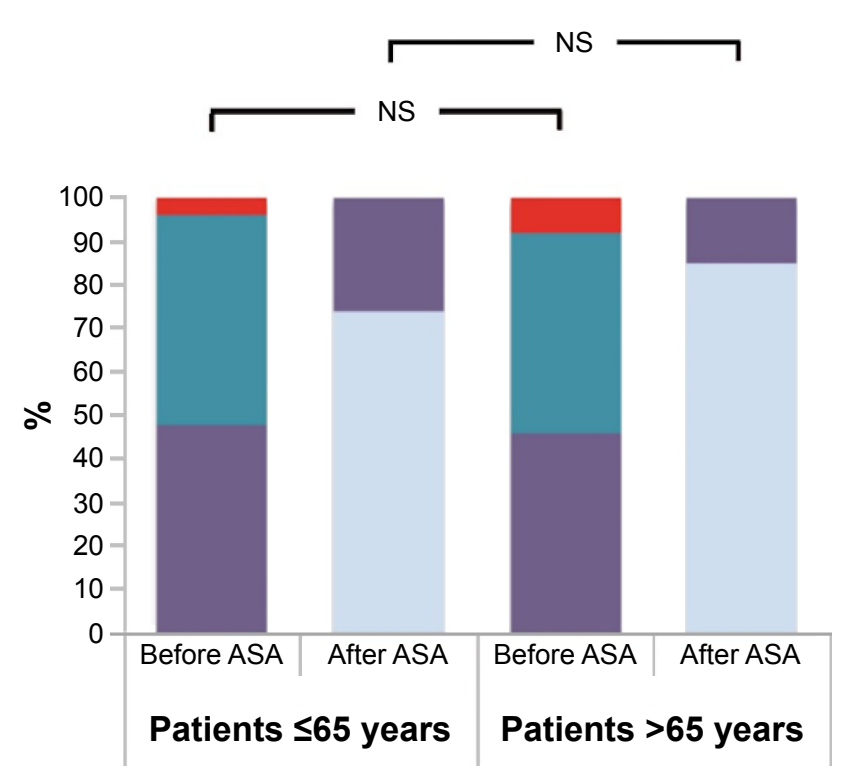

NYHA4 NYHA3 NYHA2 NYHA1

Figure I Impact of alcohol septal ablation on the NYHA class before and after ASA upon follow-up.

Note: The average duration of follow-up was $22 \pm 19$ and $16 \pm 15$ months for patients under and over 65 years old, respectively $(P=0.354)$.

Abbreviations: ASA, alcohol septal ablation; NS, non significant; NYHA, New York Heart Association.

and symptoms, regardless of age, and despite baseline differences. ${ }^{6,12,13}$ Faber et al provided conflicting results finding that younger age was associated with a less favorable hemodynamic outcome. ${ }^{14}$ This could be partly explained by a higher basal interventricular septal thickness in younger patients at baseline, as reported by Gietzen et al..$^{6,13}$ Anyway, all these studies confirm that the results of ASA on the elderly are at least as good as on younger patients up to 12 months. ${ }^{6,12}$ Our study confirms these results with an average follow-up of $16 \pm 15$ months.

We found a higher rate of major acute in-hospital cardiac events following ASA in elderly patients compared with younger patients. These findings are consistent with the previous study of Leonardi et al, who have reported higher procedural complication rates for elderly patients in comparison to younger patients. ${ }^{12} \mathrm{~A}$ recent study among 1,275 highly symptomatic patients treated with ASA demonstrated that age was an independent predictor of all-cause mortality over a follow-up of 5.7 years. ${ }^{15}$ If the influence of age on long-term all-cause mortality seems logical, its impact on the procedural complication rate is still to confirm. In our cohort, by univariate analysis, absolute age and age over 65 years old are associated with an increased risk for acute procedural complication, but no longer after multivariate analysis. Whether the sample of our study is too small for allowing enough power to differentiate risk factors for procedural complications remains to be clarified. We cannot overlook that there were two deaths among elderly patients, whereas there was none among younger patients. However, the highest rate of complication among elderly in previous studies was wildly influenced by the difference of access site bleeding: all the procedures were performed with transfemoral arterial access. ${ }^{12}$ In our cohort, most of the procedures were performed through radial access, which had a protective effect by univariate analysis. Although the impact of age on postprocedural complications was no longer significant by multivariate analysis, our study is probably underpowered to discriminate independent predictor of MACE. The trend of increased risk associated with age after multivariate analysis, in agreement with previous studies; suggests that ASA is associated with an increased rate of complications among elderly patients.

\section{Limitations}

First, our study is a retrospective observational study conducted at a single center, and, therefore, unmeasured confounding factors may influence the observed associations. Second, as aforesaid, the sample of our study is probably too small for allowing enough power to discriminate age as a risk factor for adverse cardiac events following ASA. However, the lower impact of age after multivariate analysis highlights the weight of comorbidities and confounding factors in the age-related procedural complications. Finally, our study focused on ASA and did not integrate a control group with optimal medical treatment alone or myomectomy.

\section{Conclusion}

Although it is considered as disease of the young age and because of its age-related penetrance, obstructive HCM is commonly diagnosed in the elderly, which are frequently challenged for surgical management. Consequently, symptomatic patients despite optimal medical treatment referred for ASA have increased. Our study shows that elderly patients referred for ASA have the same benefits as younger patients through an average follow-up of $16 \pm 15$ months. However, elderly patients have more complications including mortality events.

\section{Disclosure}

The authors report no conflicts of interest in this work.

\section{References}

1. Olivotto I, Ommen SR, Maron MS, Cecchi F, Maron BJ. Surgical myectomy versus alcohol septal ablation for obstructive hypertrophic cardiomyopathy. Will there ever be a randomized trial? J Am Coll Cardiol. 2007;50(9):831-834. 
2. Sorajja P, Ommen SR, Holmes DR Jr, et al. Survival after alcohol septal ablation for obstructive hypertrophic cardiomyopathy. Circulation. 2012; 126(20):2374-2380.

3. Veselka J, Krejci J, Tomasov P, Zemanek D. Long-term survival after alcohol septal ablation for hypertrophic obstructive cardiomyopathy: a comparison with general population. Eur Heart J. 2014;35(30): 2040-2045.

4. Veselka J, Krejci J, Tomasov P, et al. Survival of patients $\leq 50$ years of age after alcohol septal ablation for hypertrophic obstructive cardiomyopathy. Can J Cardiol. 2014;30(6):634-638.

5. Steggerda RC, Damman K, Balt JC, Liebregts M, ten Berg JM, van den Berg MP. Periprocedural complications and long-term outcome after alcohol septal ablation versus surgical myectomy in hypertrophic obstructive cardiomyopathy: a single-center experience. JACC Cardiovasc Interv. 2014;7(11):1227-1234.

6. Veselka J, Duchonova R, Palenickova J, et al. Age-related hemodynamic and morphologic differences in patients undergoing alcohol septal ablation for hypertrophic obstructive cardiomyopathy. Circ J. 2006; 70(7):880-884.

7. Maron BJ. Hypertrophic cardiomyopathy: a systematic review. JAMA. 2002;287(10):1308-1320.

8. Maron BJ, McKenna WJ, Danielson GK, et al. American college of cardiology/European society of cardiology clinical expert consensus document on hypertrophic cardiomyopathy. A report of the American college of cardiology foundation task force on clinical expert consensus documents and the European society of cardiology committee for practice guidelines. Eur Heart J. 2003;24(21):1965-1991.

9. Gersh BJ, Maron BJ, Bonow RO, et al. 2011 ACCF/AHA guideline for the diagnosis and treatment of hypertrophic cardiomyopathy: executive summary: a report of the American College of Cardiology Foundation/American Heart Association Task Force on Practice Guidelines. Circulation. 2011;124(24):2761-2796.
10. Fay WP, Taliercio CP, Ilstrup DM, Tajik AJ, Gersh BJ. Natural history of hypertrophic cardiomyopathy in the elderly. J Am Coll Cardiol. 1990; 16(4):821-826.

11. Lever HM, Karam RF, Currie PJ, Healy BP. Hypertrophic cardiomyopathy in the elderly. Distinctions from the young based on cardiac shape. Circulation. 1989;79(3):580-589.

12. Leonardi RA, Townsend JC, Patel CA, et al. Alcohol septal ablation for obstructive hypertrophic cardiomyopathy: outcomes in young, middle-aged, and elderly patients. Catheter Cardiovasc Interv. 2013; 82(5):838-845.

13. Gietzen FH, Leuner CJ, Obergassel L, Strunk-Mueller C, Kuhn H. Transcoronary ablation of septal hypertrophy for hypertrophic obstructive cardiomyopathy: feasibility, clinical benefit, and short term results in elderly patients. Heart. 2004;90(6):638-644.

14. Faber L, Welge D, FassbenderD, Schmidt HK, Horstkotte D, Seggewiss H. One-year follow-up of percutaneous septal ablation for symptomatic hypertrophic obstructive cardiomyopathy in 312 patients: predictors of hemodynamic and clinical response. Clin Res Cardiol. 2007; 96(12):864-873.

15. Veselka J, Jensen MK, Liebregts M, et al. Long-term clinical outcome after alcohol septal ablation for obstructive hypertrophic cardiomyopathy: results from the Euro-ASA registry. Eur Heart J. 2016;37(19): 1517-1523.
Clinical Interventions in Aging

\section{Publish your work in this journal}

Clinical Interventions in Aging is an international, peer-reviewed journal focusing on evidence-based reports on the value or lack thereof of treatments intended to prevent or delay the onset of maladaptive correlates of aging in human beings. This journal is indexed on PubMed Central, MedLine,

\section{Dovepress}

CAS, Scopus and the Elsevier Bibliographic databases. The manuscript management system is completely online and includes a very quick and fair peer-review system, which is all easy to use. Visit http://www.dovepress. com/testimonials.php to read real quotes from published authors. 